\title{
PENENTUAN DAERAH PENANGKAPAN POTENSIAL IKAN TONGKOL (Euthynnus sp.) BERDASARKAN CITRA SATELIT KLOROFIL-A DI PALABUHANRATU, JAWA BARAT
}

\section{Determination of Mackarel Tuna (Euthynnus sp.) Potential Fishing Ground Based on Clorophyll-A Satellite Image in Palabuhanratu Jawa Barat}

Oleh:

\author{
Mandala Ekaputra ${ }^{1}$, Herman Hamdani², dan Ibnu Bangkit BS², Izza Mahdiana \\ Apriliani $^{2}$ \\ ${ }^{1}$ Prodi Perikanan Fakultas Perikanan dan Ilmu Kelautan Unpad \\ ${ }^{2}$ Fakultas Perikanan dan Ilmu Kelautan Unpad \\ Korespondensi: mandala_nando@rocketmail.com
}

\begin{abstract}
ABSTRAK
Sumberdaya ikan tongkol (Euthynnus sp.) adalah salah satu sumberdaya perikanan paling dominan dan bernilai ekonomis yang cukup tinggi dan juga merupakan hasil perikanan yang menjadi target tangkapan nelayan. Salah satu parameter osenografis yang dapat digunakan untuk mengetahui informasi tersebut adalah klorofil-a. Pengukuran klorofil-a di suatu perairan dapat dilakukan dengan menggunakan metode langsung maupun metode tidak langsung (dengan menggunakan citra satelit). Salah satu satelit penginderaan jauh yang dapat mendeteksi dan menunjukkan klorofil-a adalah satelit Aqua-MODIS. Tujuan dari penelitian ini adalah untuk menentukan hubungan antara sebaran klorofila dengan hasil tangkapan dan menentukan daerah penangkapan potensial ikan tongkol di perairan Palabuhanratu. Metode penelitian yang digunakan yaitu dengan metode analisis spasial. Data spasial primer di perairan Palabuhanratu berupa data klorofil-a, dan data produksi penangkapan ikan tongkol selama 5 tahun terakhir. Data primer tersebut diolah dengan menggunakan software dan dianalisis spasial secara deskriptif. Hasil penelitian ini menunjukkan tingkat hubungan korelasi sangat lemah dengan nilai koefisien korelasi $(r)$ yaitu 0,0811 dengan koefisien determinasinya sebesar 0,066. Berdasarkan dari hasil penilaian kategori DPI, terdapat dua titik koordinat yang termasuk kedalam kategori DPI potensial.
\end{abstract}

Kata kunci: citra satelit, daerah penangkapan potensial, ikan tongkol, klorofil-A

\begin{abstract}
Mackarel Tuna resources (Euthynnus sp) are one of the most dominant and high economic value fishery resources which are fishery products that are targeted for fishing catches. One of the oceanographic parameters that can be used is sea surface temperature. Measurement of chlorophyll-a can be done using the direct method or indirect. One of the remote sensing satellites that can detect and show chlorophyll-a is the Aqua - MODIS satellite. The purpose of this study is to determine the correlations between the distribution of chlorophyll-a with mackerel tuna catches and determine the potential catch areas of mackerel tuna on the Palabuhanratu. The research method used is the spatial analysis method. Primary spatial data on the Palabuhanratu consists of chlorophyll-a data, and production data on mackarel tuna for the last 5 years. The primary data is processed using software and analyzed spatially descriptively. The results of this study indicate that the level of correlation is very weak with the value of the correlation coefficient $(r)$ is 0.0811 with a determination coefficient is 0.066 .
\end{abstract}


Based on the assessment of fishing area, there are 2 coordinate points of mackarel tuna fishing that can be categorized as potential fishing ground.

Key words: chlorophyll- $A$, mackarel tuna, potential catching areas, satellite imagery

\section{PENDAHULUAN}

PPN Palabuhanratu terletak di Desa Palabuhanratu, Kabupaten Sukabumi, Provinsi Jawa Barat. Wilayah Palabuhanratu ini terletak di Pantai Selatan Jawa yang juga berhadapan dengan Samudera Hindia, hal itu secara tidak langsung terlindung dari gelombang laut dikarenakan wilayah Palabuhanratu tersebut berbentuk teluk. Teluk Palabuhanratu secara geografis berada pada posisi 60 54' 12” - 7o 5’ 57,48” LS dan 106 20’ 57,48” - 106 36’ 0,36” BT (Astrini dalam Yundari 2005). Wilayah ini telah dipilih dan ditetapkan sebagai salah satu sentra pengembangan industri pada program industrialisasi perikanan, sementara komoditas unggulan yang dikembangkan untuk bahan baku industri pengolahan adalah tongkol, selain tuna dan cakalang (Kementerian Kelautan dan Perikanan 2015).

Ikan tongkol (Euthynnus sp.) termasuk sumberdaya ikan yang dominan dan bernilai ekonomis. Ikan tongkol juga merupakan hasil perikanan yang menjadi target tangkapan para nelayan dan menjadi salah satu komoditas utama ekspor Indonesia. Tahun 2011, nilai produksi ikan tongkol mencapai Rp 3,3 M (Mujib et al 2013), pada tahun 2015 produksi komoditas ikan tongkol meningkat sebesar 5,65\% dari tahun sebelumnya (Kementrian Kelautan dan Perikanan 2015).

Daerah-daerah penangkapan ikan di perairan itu bersifat dinamis, akan selalu berubah dan berpindah mengikuti pergerakan kondisi lingkungan yang secara alamiahnya ikan-ikan akan memilih habitatnya yang lebih sesuai. Habitat ikan tersebut akan sangat dipengaruhi oleh beberapa faktor antara lain kondisi dan parameter oseonografi perairan seperti konsentrasi klorofil-a laut, salinitas, suhu permukaan laut, cuaca dan lainnya yang akan berpengaruh pada dinamika dan pergerakan air laut, baik secara vertikal maupun horizontal. Seperti halnya peristiwa kenaikan air dari dasar laut ke permukaan laut, menghasilkan perbedaan gradien suhu yang dinamakan upwelling. Daerah yang terjadi upwelling, biasanya memiliki konsentrasi klorofil-a yang tinggi dan juga menjadi tempat berkumpulnya ikan-ikan dikarenakan klorofil-a adalah salah satu sumber makanan ikan. Daerah seperti itu disebut dengan fishing ground.

Parameter laut tersebut diperoleh dengan menggunakan pengukuran langsung yaitu dengan metode survey lapangan. Selain itu dapat pula menggunakan satelit penginderaan jauh. Dengan mengetahui parameter tersebut, saat satelit melewati perairan Indonesia, kita akan mengetahui daerahdaerah yang diduga terdapat ikan-ikan. Informasi-informasi tersebut dapat digunakan oleh para nelayan untuk penangkapan ikan, sehingga penangkapan ikan menjadi lebih efektif dan efisien apabila tempat ikan berada atau berkumpul dapat diduga lebih awal.

Tingkat produktivitas perairan dapat dilihat dari konsentrasi klorofil yang ada di perairan tersebut, hal itu dapat menjadi daya tarik bagi ikan-ikan pelagis yang bersifat plankton feeder (Effendie 2002). Klorofil-a adalah salah satu pigmen paling dominan yang ada pada fitoplankton dan sangat berperan dalam melakukan proses fotosintesis. Di bumi ini, ekosistem bahari hampir seluruhnya bergantung pada aktivitas fotosintesis tumbuhan bahari atau fitoplankton (Nybakken 1992).

Hal-hal yang dilakukan untuk menentukan daerah penangkapan ikan yang dilakukan oleh para nelayan pada umumnya masih bersifat tradisional, sehingga masih dirasa kurang efektif. Para nelayan menentukan daerah penangkapan ikan dengan hanya berdasarkan pada pengalaman yang turuntemurun dengan cara melihat tanda-tanda alam, seperti buih-buih yang terdapat di permukaan laut, melihat ada atau tidaknya kawanan burung di permukaan laut, dan lainnya. Dikarenakan para nelayan belum mengetahui lokasi yang potensial untuk menangkap ikan-ikan tersebut menyebabkan 
ketidakpastian hasil tangkapan, sehingga para nelayan tersebut harus menjelajah dan mencari tandatanda alam, namun biaya operasional penangkapan menjadi lebih tinggi karena tingginya biaya bahan bakar kapal (Muchlisin et al. 2012 dalam Demena et al. 2017). Hal tersebut dapat menjadi pendorong untuk memanfaatkan teknologi satelit atau pengidraan jauh dalam mengamati fenomena oseanografis khususnya klorofil-a.

Dalam 10 tahun terakhir ini, banyak dilakukan aplikasi teknologi penginderaan jauh dan penelitian yang mendalam (Mujib et al. 2013). Perkembangan teknologi pada bidang penginderaan jarak jauh semakin berkembang, oleh karena itu dapat kita manfaatkan untuk memperoleh informasi daerah penangkapan ikan agar dapat meningkatkan hasil tangkapan nelayan. Oleh karena hal tersebut, perlu dilakukan penelitian tentang sebaran klorofil-a di perairan Teluk Palabuhanratu untuk menduga daerah penangkapan potensial ikan tongkol.

\section{METODE PENELITIAN}

Dalam penelitian ini pengumpulan data yang dilakukan, diperoleh di perairan Teluk Palabuhanratu dengan fishing base Pelabuhan Perikanan Nusantara (PPN) Palabuhanratu. Penelitian ini dilakukan pada bulan Januari 2019 dan pengolahan data dilakukan pada bulan Februari 2019.

Metode penelitian yang digunakan pada penelitian ini yaitu dengan menggunakan metode analisis spasial. Data spasial primer di perairan Palabuhanratu berupa data klorofil-a, dan data produksi penangkapan ikan tongkol selama 5 tahun terakhir. Data klorofil-a diperoleh dari citra satelit yang telah diunduh dari website; http://oceancolor.gsfc.nasa.gov/cms, sedangkan data produksi penangkapan ikan tongkol didapat dari PPN Pelabuhanratu. Selain itu, untuk validasi data posisi penangkapan ikan yang diperoleh, maka dilakukan wawancara dengan beberapa nelayan di daerah PPN Palabuhanratu. Selanjutnya dilakukan pengolahan data pada data primer tersebut menggunakan suatu software dan dilakukan analisis spasial secara deskriptif.

Analisis yang digunakan pada penelitian ini untuk mengetahui hubungan klorofil-a dengan hasil tangkapan adalah analisis korelasi. Nilai koefisien korelasi adalah: $-1 \leq \mathrm{r} \leq+1$. Semakin tinggi korelasinya, hubungan antara koefisien tersebut semakin erat (Tabel 1). Nilai korelasi ( $r$ ) dapat dihitung dengan rumus sebagai berikut (Sugiyono 2011):

$$
r_{x y}=\frac{\sum x y}{\sqrt{x^{2} y^{2}}}
$$

Keterangan:

$r_{x y}:$ Nilai Korelasi variable $\mathrm{x}$ dengan $\mathrm{y}$

$x:(\mathrm{xi}-\mathrm{x})$

$y:\left(\mathrm{yi}_{\mathrm{i}}-\overline{\mathrm{y}}\right)$

Berdasarkan analisis korelasi terdapat angka yang biasa disebut dengan koefisien determinasi $\left(r^{2}\right)$ yang besarnya sama dengan kuadrat nilai koefisien korelasi. Koefisien ini disebut juga koefisien penentu, karena varian yang terjadi pada variabel dependen (hasil tangkapan ikan tongkol) dapat dijelaskan dengan varian yang terjadi pada variabel independen (Sugiyono 2011).

Jika analisis korelasi menunjukkan klorofil-a dengan hasil tangkapan ikan tongkol tidak berkorelasi, maka selanjutnya digunakan analisis deskriptif. Data yang dilakukan analisis secara deskriptif merupakan data bulanan selama lima tahun terakhir (2014-2018). Data tersebut disajikan dalam bentuk grafik.

Daerah penangkapan ikan dapat ditentukan menggunakan metode skoring. Terdapat tiga indikator yang digunakan, yaitu ukuran panjang hasil tangkapan, jumlah hasil tangkapan klorofil-a. Pengelompokkan indikator DPI dapat dilihat pada Tabel 2. 
Tabel 1. Hubungan koefisien korelasi

\begin{tabular}{cc}
\hline Nilai Korelasi & Hubungan \\
\hline 0 & Korelasi tidak ada \\
$0-0,25$ & Korelasi sangat lemah \\
$0,25-0,5$ & Korelasi sedang \\
$0,5-0,75$ & Korelasi kuat \\
$0,75-0,99$ & Korelasi sangat kuat \\
1 & Korelasi sempurna \\
\hline
\end{tabular}

Sumber : Sarwono 2006 dalam Prayoga et al (2017)

Tabel 2. Pengelompokan indikator DPI

\begin{tabular}{lll}
\hline & \multicolumn{1}{c}{ Kriteria } & \multicolumn{1}{c}{ DPI } \\
\hline Ukuran & Panjang ikan $\geq$ LM (layak tangkap) & Potensial \\
& Panjang ikan $<$ LM (tidak layak tangkap) & Tidak potensial \\
Jumlah Hasil & Jumlah Tangkapan $\geq$ Jumlah Tangkapan rata- & Potensial \\
Tangkapan & rata (tinggi) & \\
& Jumlah Tangkapan $<$ Jumlah Tangkapan rata- & Tidak potensial \\
& rata (rendah) & \\
Klorofil-a & Klorofil-a banyak & Potensial \\
& Klorofil-a sedang & Sedang \\
& Klorofil-a sedikit & Tidak potensial \\
\hline
\end{tabular}

Adapun bobot yang ditentukan dalam setiap indikator tersebut dapat dilihat pada Tabel 3 . Pengaruh ketiga indikator terhadap penentuan DPI diasumsikan sama. Setelah diperoleh bobot masingmasing indikator, kemudian dijumlahkan. Hal terakhir yang dilakukan dalam penentuan DPI ini yaitu dengan cara melakukan pengelompokkan nilai bobot gabungan yang merupakan hasil penjumlahan 3 indikator menjadi dua kelompok, antara lain:

1. Jika bobot gabungan berada dikisaran tertinggi, maka DPI tersebut dikategorikan DPI potensial.

2. Jika bobot gabungan berada dikisaran terendah, maka DPI tersebut dikategorikan DPI yang kurang potensial.

Tabel 3. Penilaian indikator DPI

\begin{tabular}{|c|c|c|c|}
\hline \multicolumn{3}{|c|}{ Indikator DPI } & \multirow[b]{2}{*}{ Kategori DPI } \\
\hline $\begin{array}{c}\text { Jumlah tangkapan } \\
(\mathrm{kg})\end{array}$ & $\begin{array}{l}\text { Ukuran } \\
(\mathrm{cm})\end{array}$ & $\begin{array}{l}\text { Klorofil-a } \\
\left(\mathbf{m g} / \mathbf{m}^{3}\right)\end{array}$ & \\
\hline$\geq 187(2)$ & $\geq 40(2)$ & $\begin{array}{c}\geq 1(3) \\
0.31-1(2)\end{array}$ & $\begin{array}{c}\text { Potensial (6-7) } \\
\text { Sedang (5) }\end{array}$ \\
\hline$<187(1)$ & $<40(1)$ & $<0,3(1)$ & Tidak potensial (3-4) \\
\hline
\end{tabular}




\section{HASIL DAN PEMBAHASAN}
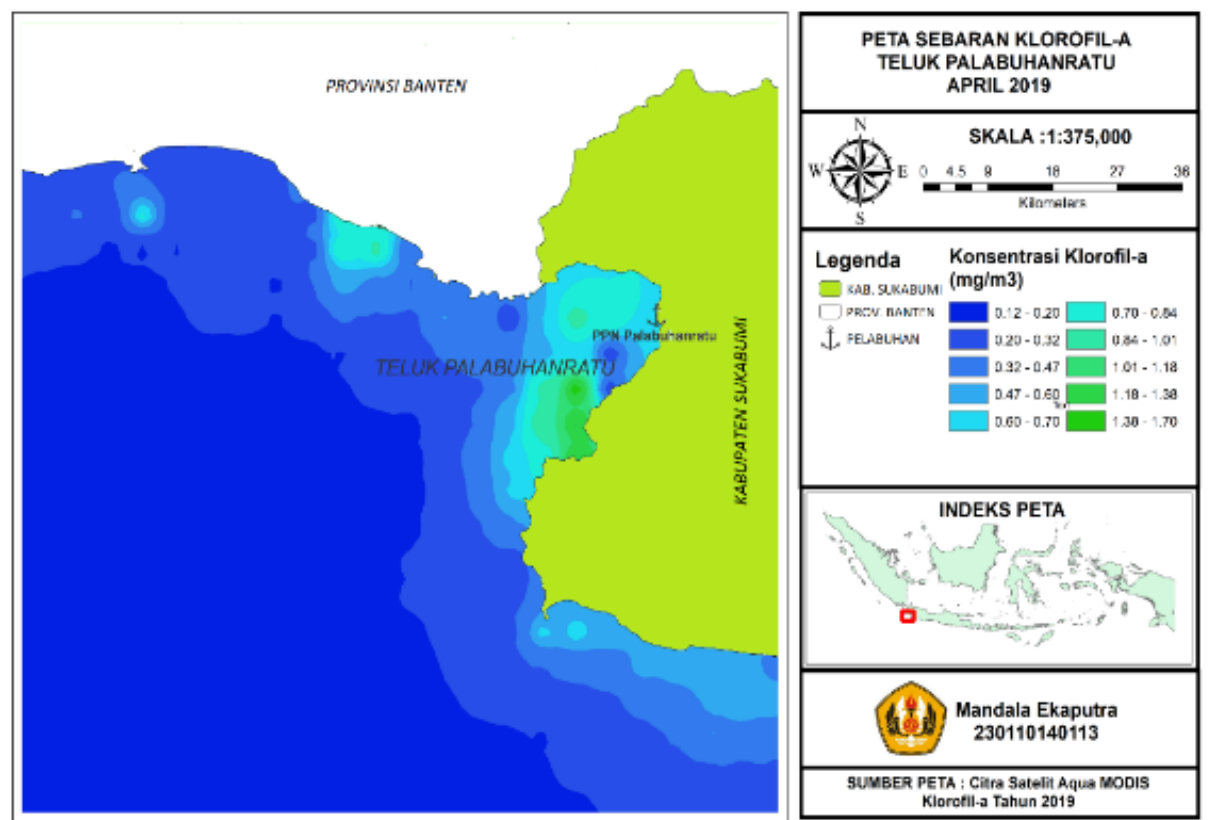

Gambar 1. Peta Sebaran Sebaran Klorofil-a Bulan April 2019

Gambar 1 menunjukan sebaran Klorofil-a di perairan Palabuhanratu selama 5 tahun terakhir, yaitu dari tahun 2014-2018. Sebaran Klorofil-a yang terjadi pada musim Barat (Bulan Desember, Januari, dan Februari) terlihat lebih tinggi jika dibandingkan dengan sebaran Klorofil-a yang terjadi pada musim Timur (Juni, Juli, dan Agustus), musim peralihan I (Maret, April, dan Mei) dan musim peralihan II (September, Oktober, dan November). Sebaran Klorofil-a terlihat menurun ketika memasuki musim peralihan I (Maret, April, Mei), tepatnya menurun pada bulan maret. Sebaran klorofil-a mulai mengalami mengalami kenaikan pada bulan Juni yaitu pada musim timur (sebaran klorofil-a).

Berdasarakan data yang diperoleh, selama lima tahun terakhir (2014-2018) nilai sebaran klorofil tertinggi terjadi di bulan Desember tahun 2018 dan bulan Februari 2017 (Gambar 2). Tingginya sebaran klorofil-a pada bulan Desember 2018 dan bulan Februari 2017 diduga karena terjadinya fenomena upwelling. Upwelling adalah peristiwa naiknya massa air laut dari lapisan bawah ke atas permukaan laut. Hembusan angin yang mendorong berkumpulnya air pada suatu permukaan mengakibatkan kosongnya massa air pada bagian lain, yang mengakibatkan massa air laut yang berasal dari bawah menggantikan kekosongan yang berada di permukaan. Naiknya air ini membawa air yang memiliki salinitas tinggi, suhunya lebih dingin, dan memiliki nutrien yang kaya ke permukaan (Nontji 1993). Selain itu, Selatan Jawa merupakan daerah upwelling musiman (Yoga et al. 2014).

Proses upwelling tersebut dapat terlihat tanda-tandanya dari sebaran konsentrasi klorofil-a yang bervariasi secara spasial dan temporal. Konsentrasi klorofil-a lebih rendah di perairan lepas pantai dan lebih tinggi di perairan pantai dan pesisir, akan tetapi pada daerah tertentu di perairan lepas pantai dapat ditemukan konsentrasi klorofil-a dengan jumlah yang cukup tinggi, hal tersebut merupakan fenomena upwelling (Ramansyah 2009). Sebaran Klorofil-a terendah terjadi di bulan November tahun 2016, penyebabnya merupakan curah hujan yang tinggi di perairan Palabuhanratu sehingga intensitas cahaya matahari yang masuk ke perairan kurang memadai. 


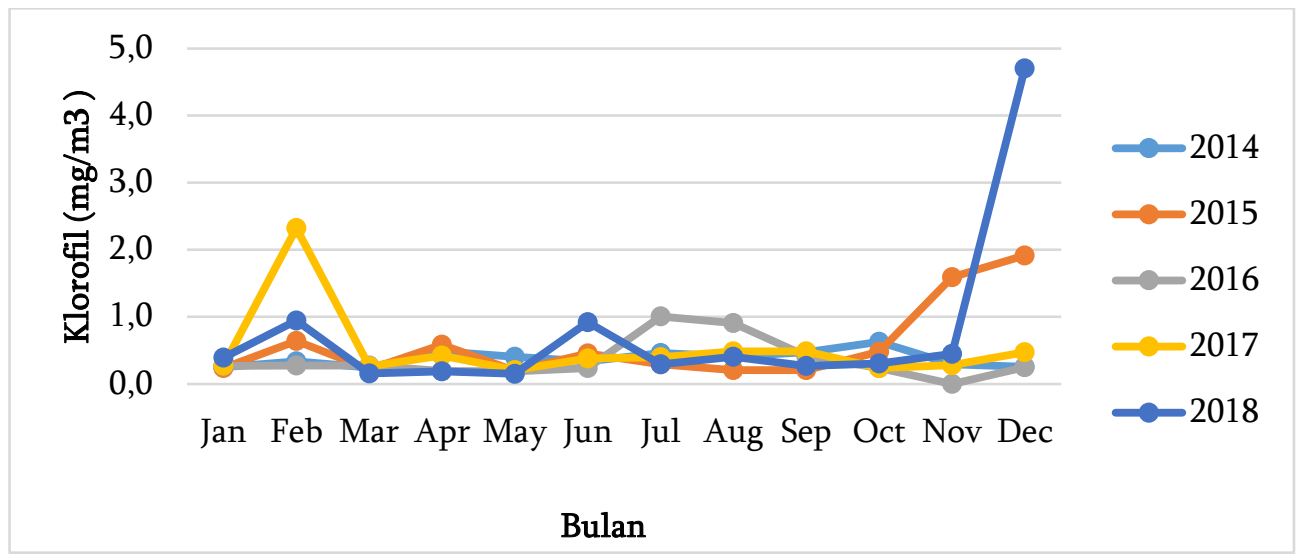

Gambar 2. Nilai sebaran klorofil-a tahun 2014-2018 di perairan Palabuhanratu

Perairan Palabuhanratu memiliki sebaran Klorofil-a yang relatif tinggi pada musim barat dan relatif rendah pada musim Peralihan I. Nilai kandungan pada klorofil-a cenderung berfluktuasi setiap harinya. Menurut Mujib et al (2013) nilai yang terkandung pada klorofil-a di perairan Palabuhanratu, dipengaruhi atau disebabkan oleh beberapa faktor yaitu masukan nutrien dari daerah pantai dan intensitas cahaya matahari.

Selama tahun 2014 sampai dengan tahun 2018, hasil tangkapan ikan tongkol berfluktuasi setiap bulan. Tahun 2014, hasil tangkapan tertinggi itu terjadi pada bulan Oktober dengan hasil tangkapan sebesar 322,60 ton dan hasil tangkapan terendah terjadi di bulan Januari dengan hasil tangkapan 0 ton yang berarti tidak mendapatkan hasil tangkapan ikan tongkol sama sekali. Tahun 2015, hasil tangkapan tertinggi terjadi di bulan Juli dengan hasil tangkapan sebesar 132,58 ton dan hasil tangkapan terendah terjadi di bulan April yaitu sebesar 0,18 ton. Tahun 2016, hasil tangkapan tertinggi terjadi di bulan September yaitu sebesar 11,21 ton dan mendapatkan hasil tangkapan terendah di bulan Januari yaitu 0 ton yang berarti tidak mendapatkan hasil tangkapan ikan tongkol sama sekali. Pada tahun 2017, tangkapan tertinggi diperoleh di bulan Agustus yaitu sebesar 121,031 ton dan mendapatkan hasil tangkapan terendah di bulan November yaitu sebesar 0,32 ton. Tahun 2018, hasil tangkapan tertinggi terjadi di bulan Oktober yaitu sebesar 363,35 ton dan mendapatkan hasil tangkapan terendah pada bulan Februari yaitu 0 ton yang berarti tidak mendapatkan hasil tangkapan ikan tongkol (Gambar 3).

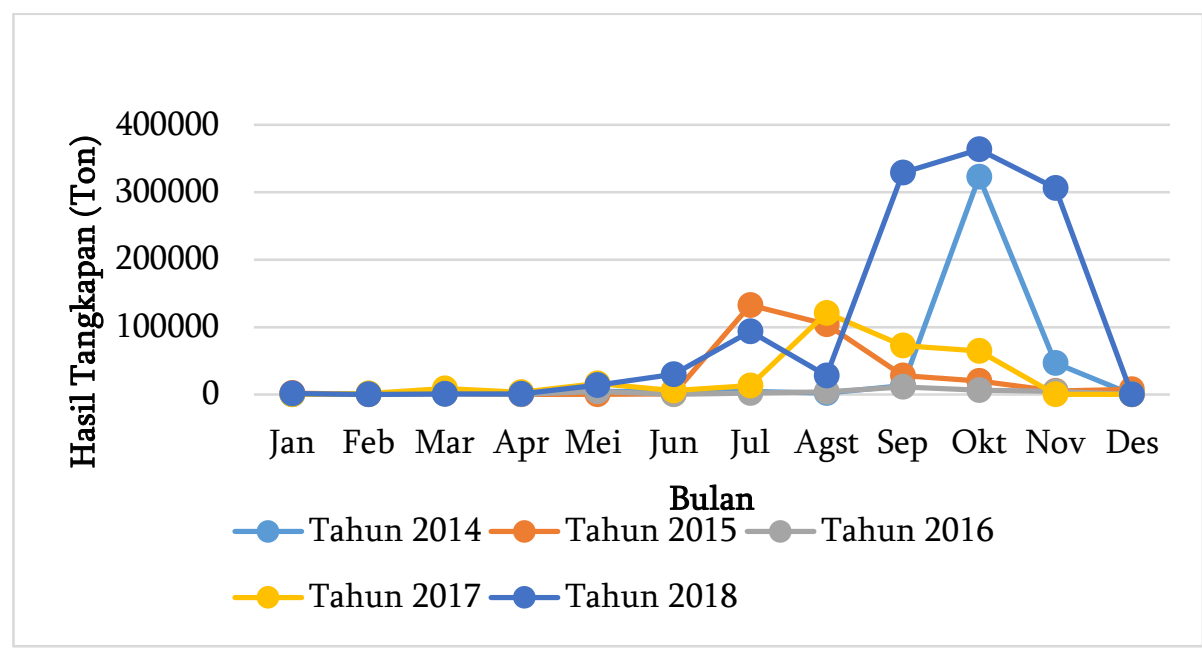

Gambar 3 Fluktuasi hasil tangkapan ikan tongkol tahun 2014-2018

Berdasarkan data yang diperoleh selama lima tahun terakhir (2014-2018), hasil tangkapan ikan tongkol tertinggi terjadi pada tahun 2018 diikuti tahun 2014, dan hasil tangkapan ikan tongkol terendah terjadi pada tahun 2016 (Gambar 3). Hal tersebut diduga karena hasil tangkapan tahun-tahun 
sebelumnya yaitu tahun 2014-2015 sumberdaya ikan tongkol dieksploitasi secara berlebihan. Eksploitasi yang berlebih pada tahun-tahun puncak produksi, memiliki kecenderungan akan diikuti penurunan pada produksi yang sangat tajam pada tahun selanjutnya/berikutnya (Inaya 2004 dalam Zakiah 2015).

Jika dilihat berdasarkan musim, rata-rata dari hasil tangkapan ikan tongkol yang tertinggi terjadi pada musim peralihan 2 yaitu, pada bulan September-November dengan memiliki rata-rata hasil tangkapannya ikan tongkol sebesar 106,3 ton. Hasil tangkapan ikan tongkol tertinggi selanjutnya adalah musim timur yaitu pada bulan Juni-Agustus dengan memiliki rata-rata hasil tangkapannya ikan tongkol sebesar 36,52 ton. Urutan selanjutnya adalah pada musim peralihan 1 yaitu pada bulan MaretMei dengan memiliki rata-rata hasil tangkapan 5,13 ton dan yang terakhir yaitu hasil tangkapan terendah terjadi pada musim barat yaitu pada bulan Desember-Februari dengan memiliki rata-rata hasil tangkapannya sebesar 1,03 ton (Gambar 4). Menurut Prayoga et al (2017) tingginya hasil tangkapan pada musim perihan 2 diduga disebabkan oleh kondisi cuaca yang cukup mendukung dalam melakukan penangkapan ikan tongkol sehingga para nelayan dapat melakukan penangkapan dengan optimal. Rendahnya hasil tangkapan pada musim barat yaitu bulan Desember sampai dengan bulan Februari, diduga pada saat musim barat cuaca sedang dalam kondisi yang buruk karena tingginya curah hujan yang menyebabkan para nelayan tidak bisa melakukan kegiatan penangkapan ikan dengan optimal.

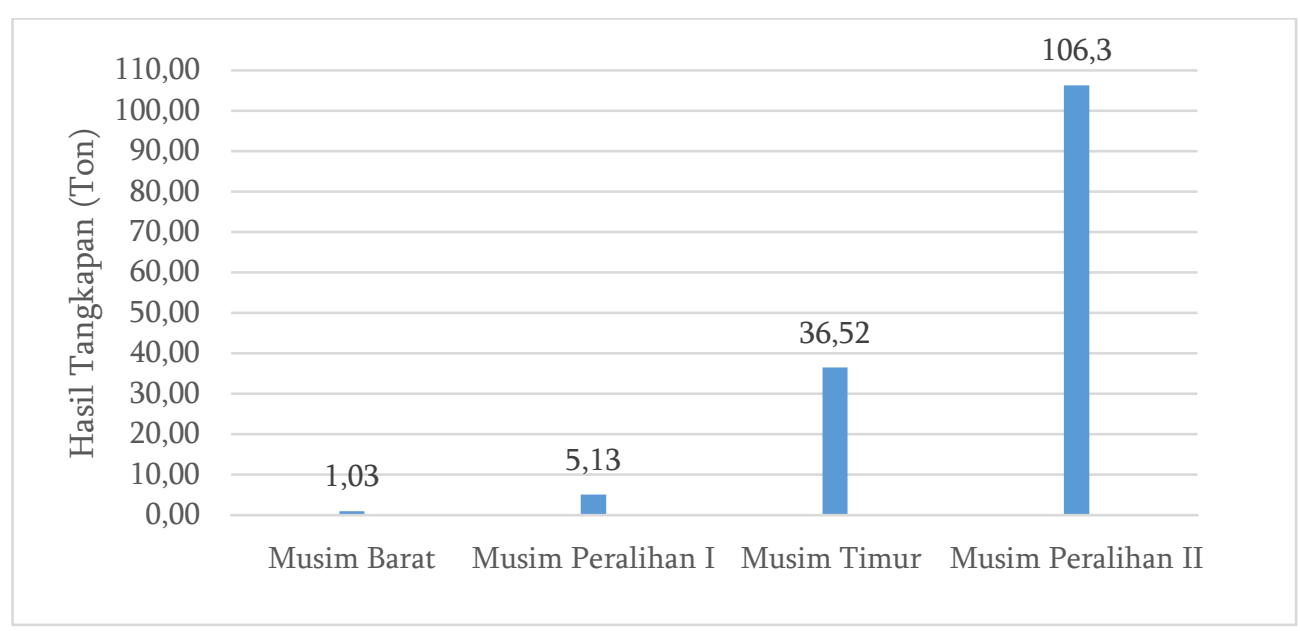

Gambar 4 Rata-rata hasil tangkapan ikan tongkol tahun 2014-2018 berdasarkan musim di perairan palabuhanratu

Hubungan sebaran klorofil-a dengan hasil tangkapan ikan tongkol dianalisis menggunakan analisis korelasi yang dilakukan berdasarkan time series tahunan selama 5 tahun (2014-2018). Berdasarkan analisis yang dilakukan, diperoleh nilai koefisien korelasi (r) yaitu 0,0811 dengan koefisien determinasinya sebesar 0,066 (Gambar 5). Menurut Sarwono (2006) dalam Prayoga et al (2017) nilai r dengan range 0,0-0,25 memiliki tingkat hubungan korelasi sangat lemah.

Berdasarkan hasil analisis korelasi (Gambar 5) tersebut menunjukan bahwa variabel hasil tangkapan ikan tongkol hanya 6,6\% dipengaruhi oleh klorofil-a, sedangkan 93,4\% dipengaruhi oleh faktor lainnya. Klorofil-a bukan satu-satunya indikator yang digunakan untuk mengidentifikasi wilayah atau daerah-daerah potensial untuk penangkapan ikan. Selain klorofil-a, terdapat indikatorindikator lainnya yang biasanya digunakan untuk menentukan daerah potensial tangkapan ikan yaitu SPL dan arus. 


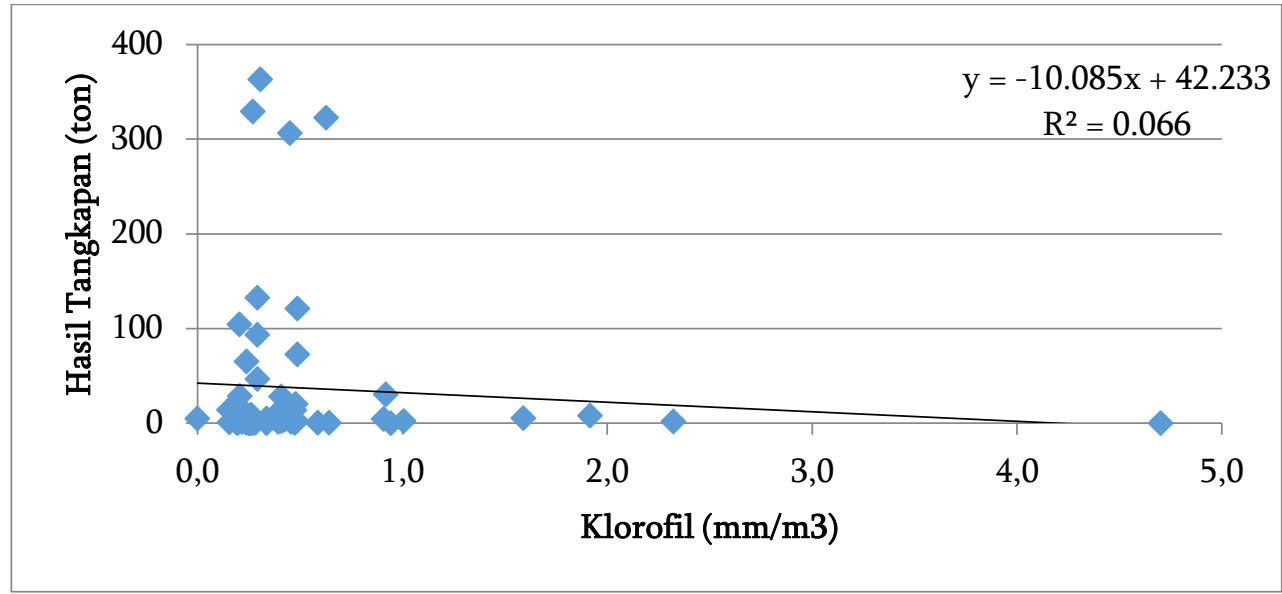

Gambar 5 Grafik regresi klorofil-a dengan hasil ikan tongkol tahun 2014-2018

Pada penelitian ini kategori daerah penangkapan ikan potensial untuk ikan tongkol dibagi menjadi 3 kategori, yaitu kategori potensial, sedang dan tidak potensial yang didasarkan pada tiga indikator. Tiga indikator tersebut adalah, jumlah hasil tangkapan ikan, ukuran ikan dan konsentrasi klorofil-a pada daerah penangkapan ikan tongkol di daerah Perairan Teluk Palabuhanratu. Kemudian dilakukan penilaian kategori daerah penangkapan ikan tongkol potensial. Hasil penentuan daerah penangkapan ikan tongkol potensial disajikan pada Tabel 4.

Tabel 4. Penilaian Kategori DPI Potensial di Wilayah Penangkapan Ikan Tongkol

\begin{tabular}{|c|c|c|c|c|c|c|c|c|c|c|}
\hline \multirow{3}{*}{$\begin{array}{l}\text { DPI } \\
\text { ke- }\end{array}$} & \multicolumn{2}{|c|}{ Posisi } & \multicolumn{6}{|c|}{ Indikator DPI } & \multirow{2}{*}{\multicolumn{2}{|c|}{ Kategori DPI }} \\
\hline & \multirow[t]{2}{*}{ Lattitude } & \multirow[t]{2}{*}{ Longitude } & \multicolumn{2}{|c|}{$\begin{array}{c}\text { Hasil } \\
\text { Tangkapan } \\
(\mathrm{Kg})\end{array}$} & \multicolumn{2}{|c|}{$\begin{array}{l}\text { Klorofil } \\
(\mathrm{mg} / \mathrm{m} 3)\end{array}$} & \multicolumn{2}{|c|}{$\begin{array}{c}\text { Ukuran } \\
\text { Panjang (cm) }\end{array}$} & & \\
\hline & & & Nilai & Bobot & Nilai & Bobot & Nilai & Bobot & $\begin{array}{c}\text { Bobot } \\
\text { total }\end{array}$ & Kategori \\
\hline 1 & $7^{0} 0^{\prime} 0^{\prime \prime}$ LS & $\begin{array}{l}106^{0} 19^{\prime} \\
48^{\prime \prime} \mathrm{BT}\end{array}$ & 140 & 1 & 0.32 & 2 & 37.2 & 1 & 4 & $\begin{array}{c}\text { Tidak } \\
\text { Potensial }\end{array}$ \\
\hline 2 & $\begin{array}{c}7^{0} 15^{\prime} 0^{\prime \prime} \\
\text { LS }\end{array}$ & $\begin{array}{l}106^{0} 21 \\
00^{\prime \prime} \mathrm{BT}\end{array}$ & 150 & 1 & 0.47 & 2 & 42.3 & 2 & 4 & $\begin{array}{c}\text { Tidak } \\
\text { Potensial }\end{array}$ \\
\hline 3 & $\begin{array}{c}7^{0} 21^{\prime} 0 ” \\
\text { LS }\end{array}$ & $\begin{array}{l}106^{0} 24 \\
00^{\prime \prime} \mathrm{BT}\end{array}$ & 130 & 1 & 0.25 & 1 & 38.6 & 1 & 3 & $\begin{array}{c}\text { Tidak } \\
\text { Potensial }\end{array}$ \\
\hline 4 & $7^{0} 9^{\prime} 0$ " LS & $\begin{array}{l}106^{0} 25^{\prime} \\
12^{\prime \prime} \mathrm{BT}\end{array}$ & 280 & 2 & 0.84 & 2 & 42.6 & 2 & 6 & Potensial \\
\hline 5 & $\begin{array}{c}7^{0} 15^{\prime} 0^{\prime \prime} \\
\text { LS }\end{array}$ & $\begin{array}{l}106^{0} 17^{\prime} \\
24 " \mathrm{BT}\end{array}$ & 130 & 1 & 0.47 & 2 & 32 & 1 & 4 & $\begin{array}{c}\text { Tidak } \\
\text { Potensial }\end{array}$ \\
\hline 6 & $\begin{array}{c}7^{0} 12^{\prime} 36^{\prime \prime} \\
\text { LS }\end{array}$ & $\begin{array}{l}106^{0} 13^{\prime} \\
12 ” \mathrm{BT}\end{array}$ & 150 & 1 & 0.31 & 2 & 33.6 & 1 & 4 & $\begin{array}{c}\text { Tidak } \\
\text { Potensial }\end{array}$ \\
\hline 7 & $\begin{array}{c}7^{0} \text { 2’ }^{\prime} 24 ” \\
\text { LS }\end{array}$ & $\begin{array}{l}106^{0} 30^{\prime} \\
00^{\prime \prime} \mathrm{BT}\end{array}$ & 150 & 1 & 0.71 & 2 & 32.1 & 1 & 4 & $\begin{array}{c}\text { Tidak } \\
\text { Potensial }\end{array}$ \\
\hline 8 & $\begin{array}{c}7^{0} 10^{\prime} 48^{\prime \prime} \\
\text { LS }\end{array}$ & $\begin{array}{l}106^{0} 23^{\prime} \\
24 ” \mathrm{BT}\end{array}$ & 140 & 1 & 0.72 & 2 & 44.7 & 2 & 5 & Sedang \\
\hline 9 & $\begin{array}{c}7^{0} 7^{\prime} 48^{\prime \prime} \\
\text { LS }\end{array}$ & $\begin{array}{c}106^{0} 19^{\prime} \\
48^{\prime \prime} \mathrm{BT}\end{array}$ & 300 & 2 & 0.33 & 2 & 28 & 1 & 5 & Sedang \\
\hline 10 & $\begin{array}{c}7^{0} 4^{\prime} 48^{\prime \prime} \\
\text { LS }\end{array}$ & $\begin{array}{l}106^{0} 27 \\
36 ” \mathrm{BT}\end{array}$ & 300 & 2 & 1.18 & 3 & 28.5 & 1 & 6 & Potensial \\
\hline
\end{tabular}


Berdasarkan tabel penilaian (Tabel 4) dapat diketahui bahwa di wilayah penangkapan ikan tongkol terdapat 6 DPI yang dikategorikan tidak potensial, 2 DPI yang dikategorikan sedang dan 2 DPI yang dikategorikan potensial. Pada DPI ke-10 jika diamati kembali ukuran hasil tangkapan ikan menunjukan bobot yang tidak layak tangkap, akan tetapi konsentrasi klorofil-a dan jumlah hasil tangkap pada DPI ke-10 menunjukan nilai yang optimum sehingga DPI tersebut dikategorikan DPI Potensial.

Peta sebaran DPI (Gambar 6) dibuat berdasarkan dengan penilaian yang telah dilakukan dengan memperhatikan jumlah hasil tangkapan ikan, ukuran ikan dan jumlah klorofil yang optimum untuk penangkapan ikan tongkol di daerah Perairan Teluk Pelabuhanratu. Dilihat dari konsentrasi klorofil-a yang tersebar di Perairan Teluk Palabuhanratu, diindikasikan bahwa wilayah penangkapan ikan tongkol juga dapat terjadi diluar wilayah atau koordinat yang terdapat pada Gambar 6.

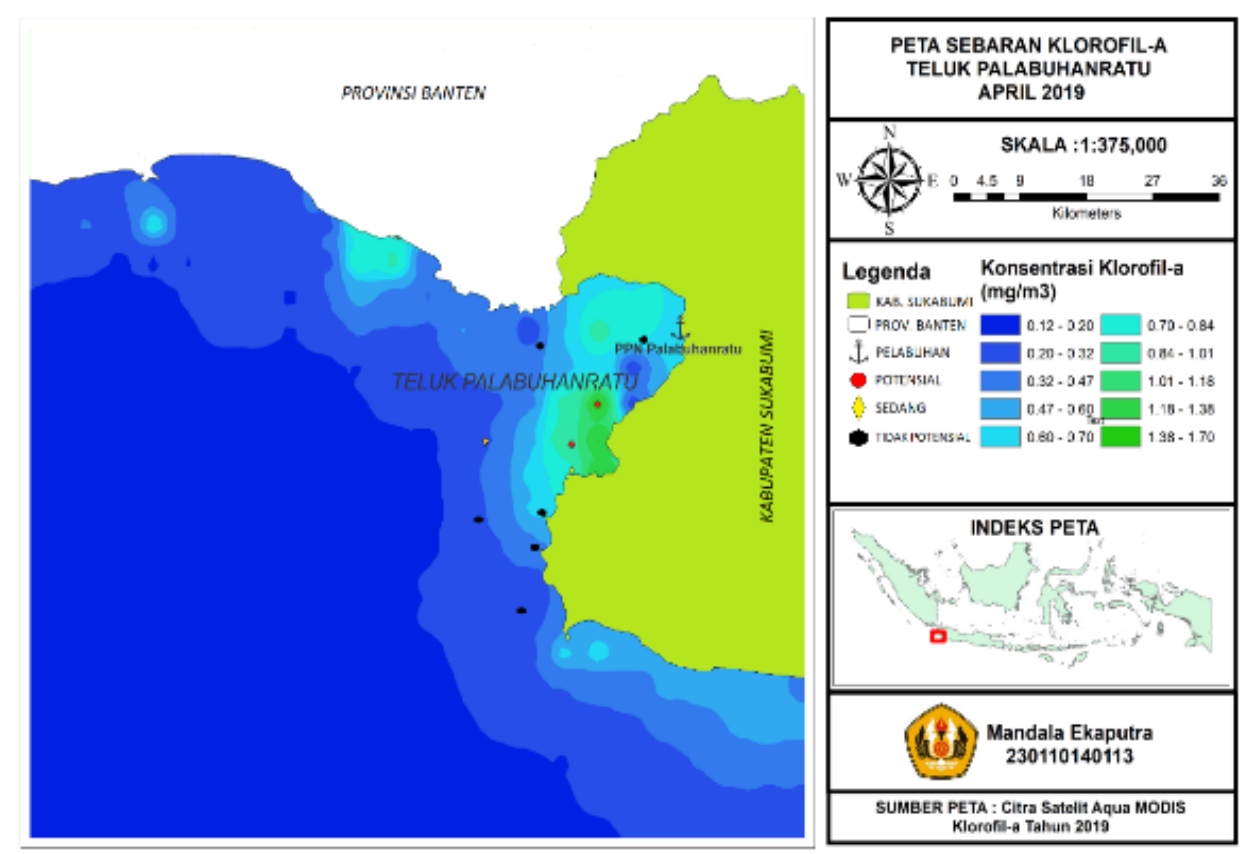

Gambar 6 Peta sebaran daerah penangkapan ikan tongkol di perairan Teluk Palabuhanratu

\section{KESIMPULAN DAN SARAN}

Hubungan sebaran klorofil-a dengan hasil tangkapan memiliki hubungan yang dapat dikatakan sangat lemah, dengan nilai koefisien korelasi sebesar 0,0811. 10 DPI di perairan Palabuhanratu diidentifikasi, terdapat 2 DPI yang termasuk ke dalam kategori daerah penangkapan potensial yaitu pada titik koordinat $7^{0}$ 9' 0" LS $106^{\circ} 25^{\prime} 12^{\prime \prime}$ BT dan 70 4' 48” LS $106^{\circ} 27^{\prime} 36^{\prime \prime}$ BT. 2 DPI yang termasuk kategori sedang $7^{0} 10^{\prime} 48^{\prime \prime}$ LS $106^{0}$ 23' 24” BT dan 70 7’ 48” LS $106^{0} 19^{\prime} 48^{\prime \prime}$ BT.

Berdasarkan hasil penelitian yang didapatkan, disarankan untuk melakukan penelitian selanjutnya mengenai penentuan daerah penangkapan ikan tongkol di Palabuhanratu diluar titik koordinat yang telah didapat dan dengan parameter oseanografi lainnya.

\section{UCAPAN TERIMAKASIH}

Ucapan terimakasih ditujukan kepada kepala serta staff PPN Palabuhanratu, nelayan di PPN Palabuhanartu yang telah memberikan izin dan informasi selama penelitian. Serta semua pihak yang sudah membantu dalam penelitian dan memberikan masukan untuk memperbaiki paper ini. 


\section{DAFTAR PUSTAKA}

Demena, Y E., E Miswar., M Musman. 2017. Penentuan Daerah Potensial Penangkapan Ikan Cakalang (Katsuwonus pelamis) Menguunakan Citra Satelit di Perairan Jayapura Selatan Kota Jayapura. Jurnal Ilmiah Mahasiswa Kelautan dan Perikanan Unsyiah. 2 (1) : 194-199.

Effendie, M.I. 2002. Biologi Perikanan. Yogyakarta: Yayasan Pustaka Nusatama. 163 hal.

KKP. Kementrian Kelautan dan Perikanan. 2015. Analisis Data Pokok Kelautan dan Perikanan 2015. Jakarta : Pusat Data, Statistik, dan Informasi.

Mujib, Z., H. Boesono, A. D. P. F. Fitri. 2013. Pemetaan Sebaran Ikan Tongkol (Euthynnus sp.) dengan Data Klorofil-a Citra Modis pada Alat Tangkap Payang (Danish-seine) di Perairan Teluk Pelabuhanratu, Sukabumi, Jawa Barat. Journal of Fisheries Utilization Management and Technology. 2 (2) : 150-160.

Nontji, A. 1993. Laut Nusantara. Jakarta: Djambatan.

Nybakken, J.W. 1992. Biologi Laut Suatu Pendekatan Ekologis. Jakarta: PT. Gramedian. 459 hal.

Prayoga, I Made Satya., I. Dewa Nyoman Nurweda Putra, I. Gusti Ngurah Putra Dirgayusa. 2017. Pengaruh Sebaran Konsentrasi Klorofil-a Berdasarkan Citra Satelit terhadap Hasil Tangkapan Ikan Tongkol (Euthynnus sp) Di Perairan Selat Bali. Journal of Marine Aquatic Science. 3(1) : 30-46.

Ramansyah, F. 2009. Penentuan Pola sebaran konsentrasi klorofil-a di selat sunda dan perairan sekitar dengan menggunakan data inderaan Aqua Modis. Skripsi. PS ITK FPIK IPB. Bogor.

Sugiyono. 2011. Statistika untuk Penelitian. Bandung: Alfabeta.

Yoga RB, Setyono H, Harsono G. 2014. Dinamika upwelling dan downwelling berdasarkan variabilitas suhu permukaan laut dan klorofil-a-a di Perairan Selatan Jawa. Jurnal Oseanografi. 3(1):57-66.

Yundari, D. 2005. Perbandingan Indeks Relatif Nilai Produksi Ikan PPN Palabuhanratu Kabupaten Sukabumi dan Provinsi Jawa Barat Dikaitkan dengan Kualitas Pemasaran Ikan yang Didaratkan. Skripsi (tidak dipublikasikan). Fakultas Perikanan dan Ilmu Kelautan. Institut Pertanian Bogor. Bogor.

Zakiah, S. 2015. Pendugaan Daerah Penangkapan Ikan Lemuru melalui Analisis Suhu Permukaan Laut dan Komposisi Hasil Tangkapan di PPP Muncar, Banyuwangi. Skripsi. Bogor: Departemen Pemanfaatan Sumberdaya Perikanan, Fakultas Perikanan dan Ilmu Kelautan, Institut Pertanian Bogor. 